\title{
Cultura Cultura
}

José Esteves Pereira)

mentira e verdade nos folhetos humorísticos de José Daniel Rodrigues da Costa

\section{"Com toda a certeza, se não for mentira"}

mentira e verdade nos folhetos humorísticos de José Daniel Rodrigues da Costa

\section{João Pedro Rosa Ferreira}

\section{(2) OpenEdition}

Journals

Edição electrónica

URL: http://journals.openedition.org/cultura/3744

DOI: $10.4000 /$ cultura.3744

ISSN: 2183-2021

Editora

Centro de História da Cultura

Edição impressa

Data de publição: 1 janeiro 2017

Paginação: 247-265

ISSN: 0870-4546

\section{Refêrencia eletrónica}

João Pedro Rosa Ferreira, " "Com toda a certeza, se não for mentira" », Cultura [Online], vol. 36 | 2017, posto online no dia 20 novembro 2019, consultado a 08 janeiro 2020. URL : http://

journals.openedition.org/cultura/3744; DOI : 10.4000/cultura.3744

Este documento foi criado de forma automática no dia 8 janeiro 2020.

(c) $\mathrm{CHAM}$ - Centro de Humanidades / Centre for the Humanities 


\title{
"Com toda a certeza, se não for mentira"
}

mentira e verdade nos folhetos humorísticos de José Daniel Rodrigues da Costa

\author{
João Pedro Rosa Ferreira
}

\section{NOTA DO AUTOR}

Fui, por duas vezes, aluno do Professor Esteves Pereira: primeiro, no mestrado em História Cultural e Política, depois, passados trinta anos, no curso de doutoramento. Devo-lhe, além de tudo o que me ensinou, a generosidade com que me disponibilizou um inédito de Hipólito da Costa, que publiquei na minha dissertação de mestrado. Os pressupostos teóricos, epistemológicos e metodológicos deste artigo são, em larga medida, tributários da sua lição, a começar pelos conceitos de facto e de fontes em história das ideias (Pereira 1992, 68-81).

"Pilatos perguntou-lhe: 'Mas, que é a verdade?"”

(João, 18, 38)

\section{"Verdade co'a mentira se mistura"}

1 A mentira (Agostinho 2007, 457-477; Constant 1796, 75-77; Derrida 2012; Kant 1997; Nietzsche 1997, 213-222) tem uma presença constante, quase obsessiva, na obra humorística de José Daniel Rodrigues da Costa. ${ }^{1} \mathrm{~A}$ começar pelos títulos dos periódicos que redigiu: se o Almocreve de Petas, cuja primeira edição foi publicada entre 1797 e 1800, a introduz através de um sinónimo em que a força da palavra surge de algum modo mitigada, o seguinte, lançado em 1801, ostenta um título que é todo ele uma declaração de princípios: Comboy de Mentiras, vindo do Reino Petista, com a fragata Verdade 
Encoberta por Capitânia. Em O Espreitador do Mundo Novo (1802), a tónica é posta na descoberta da verdade pelo óculo curioso da figura que lhe dá o nome e que aparece representada na gravura da página de rosto. No Barco da Carreira dos Tolos (1803), mentira e verdade defrontam-se nos folhetos mensais, enquanto no Hospital do Mundo (1805), o subtítulo desta "obra crítica, moral e divertida" explica que ali "é médico o desengano e enfermeiro o tempo".

2 Já na Câmara Óptica, que teve uma existência atribulada - iniciada em 1807, sofreu duas interrupções prolongadas, a primeira de vários meses, entre meados de 1808 e Dezembro do mesmo, a segunda de dois anos, entre 1809 e 1811 -, o subtítulo remete para as "vistas às avessas" que "mostram o mundo às direitas". Ali refere, significativamente, "as minhas verdades, temperadas com as petas" (Câmara Óptica, VII, 19).

3 Noutras obras, não periódicas, do universo de José Daniel Rodrigues da Costa, como as Rimas, de 1795, ou Ideias Vagas sobre Vários Assuntos (1822), afloram igualmente a verdade e o desengano, de um lado; mentiras, petas, ópios, fingimento, de outro, numa relação aparentemente dicotómica mas que por vezes assume uma forma dialéctica (Escarpit 1960, 73-92), de que é exemplo o verso "Verdade co'a mentira se mistura" (Ideias Vagas, Soneto XXII, 226).

\section{Almocreve de Petas ou Correio das Verdades?}

4 Logo no primeiro folheto do Almocreve de Petas, em Janeiro de 1797, José Daniel Rodrigues da Costa previne os leitores com a "Protestação do Author", ${ }^{2}$ habitual nas suas obras para evitar litígios e problemas com a censura. A experiência ajuda a explicar esta estratégia de defesa preventiva. Em Agosto de 1796, José Daniel requereu à Mesa do Desembargo do Paço licença para imprimir os 2. e 3.․ tomos das suas obras poéticas. O censor Francisco Xavier de Oliveira emitiu parecer favorável e até elogiou "os talentos do Author para a Poesia Comica". Não obstante, condicionou a autorização ao expurgo de algumas partes, incluindo dois epigramas "satiricos, petulantes, [qu]e ofendem a mais respeitavel Ordem da Sociedade Civil". Sublinhou a "differença entre censurar costumes, e satirisa-los", lembrando que Horácio, Pérsio e Juvenal "não corrõperão as suas Satiras com chocarrices, e ditos burlescos, que fazendo rir a plebe, enchem de indignação aos homens sisudos". Verberou ainda o requerente por ridicularizar os Círios e Festas de Arraial: "se este uso he mao, a sua reforma compete aos Prelados Ecclesiasticos, e não a hũ leigo declamador, e Poeta de profissão, a quem he só concedido escolher assũptos mundanos, para objecto dos seus golpes satiricos, e de nenhũ modo aquelles que a Religião faz sagrados por estarem debaixo da sua bandeira". Por fim, censurou a resposta a um contra-ópio do autor, "por ser assás picante, e offender a pessoa de Caetano Roldão", cujo nome fora impresso. ${ }^{3}$ José Daniel mostrou ter aprendido a lição:

Assegura, e protesta o Escritor desta Obra, que não he sua intenção remoquear, ou

alludir a pessoa alguma em particular com as palavras, e narrações ficticias, e jocosas, de que nella se serve, pois só procura facilitar por este modo a recreação do espirito, e ainda a lição de muitas cousas miudas da vida, pois os casos, que contém, são de mera invenção, sem satyras, ou invectivas aos Leitores, etc. (Almocreve, I, 8) popular da época - seriam "narrações fictícias", “de mera invenção”. No entanto, a 
"Falla de despedida do Editor desta Obra", no último folheto, em Fevereiro de 1800, acaba por desmentir essa estratégia defensiva. A troça e o sarcasmo, instrumentos de denúncia da rigidez que está na base do efeito cómico (Bergson 1991, 17-24), são constantes no retrato de Lisboa na passagem do século XVIII para o XIX, com as suas ruas, praças e becos e os tipos humanos que dão corpo e alma às petas - que, afinal, não seriam assim tão mentirosas: "fui tão louco, que devendo-lhes chamar correio das verdades, lhe puz Almocreve de Petas" (Almocreve, CXL, 2).

6 Talvez por isso emende a mão em O Espreitador do Mundo Novo (1802), quando se dirige directamente ao leitor, prometendo-lhe verdade nas histórias que ali conta:

Eu não trato de prometter nestes Folhetos cousas grandes, porque os meus talentos são pequenos; e não quero que me digão, que promettendo muito, não dou nada. 0 que asseguro he não escandalisar os ouvidos dos Leitores, seja Homem, ou Senhora, porque os hei de fazer confessar, que he verdade, o que digo, e que pinto ao natural, o que se está vendo; além de servir de lição para que os dois séxos se acautelem de tratantes, vindo por todos os lados esta Obra a ser util. Nella envolverei com o sério a juvialidade, que huma critica tal poder admittir, reprehendendo os vicios, e dando hum refrigerio aos génios melancolicos. [...] E se muitos me chamarem prégador importuno, lembrem-se, que a verdade, e a moral, devem-se estimar, como se estima o Sol, que não enjôa por apparecer todos os dias. (Espreitador, I, 6-7) ${ }^{4}$

\section{Ópios}

7 No campo oposto, o autor coloca os ópios, ${ }^{5}$ enganos, aparências que, mascarando-a, encobrem a verdade, mas que, por isso mesmo, são susceptíveis de serem denunciados e, como máscaras, arrancados para a deixarem à mostra:

Sempre do luxo foi o ópio filho,/ Que em todos se sustenta;/ Todo o que vive de ópio lhe dá vida,/ A troco de palavra mal cumprida. // Da parte do meu ópio principio,/ A castigar os vicios;/ E como o que eu disser, verdades são/ Queira o Ceo, que approveite a pregação. // Eu não vou criticar vidas alheias,/ Sim os opios do Mundo;/ A minha correcção o Mundo ature,/ E quem tiver a queixa, que se cure. (Espreitador, I, 24)

8 Já nas Rimas, editadas em 1795, José Daniel publicara um soneto dedicado aos ópios:

He ópio dar em casa huma função,/ He ópio o andar sempre sem real,/ São ópio boas festas no Natal,/ Duas noites perder no S. João.// He ópio rebentar de comilão,/ He ópio vestir bem, e comer mal,/ He ópio o ir a pé té ao Cardal,/ Com créditos de ser hum bom ladrão.// He ópio namorar quem me não quer,/ He ópio o ir levando, e não fugir,/ He ópio sopportar huma mulher.// E para o meu Soneto concluir,/ Té neste mundo hum ópio vem a ser,/ Vermos huns a chorar, outros a rir. (Rimas, 5)

9 Tal como o Almocreve de Petas merecia ter sido chamado "correio das verdades", a citação da écloga Vida de Camões, de Manuel de Faria e Sousa, surge como epígrafe apropriada à "Opíada", poema publicado ao longo dos doze folhetos de $O$ Espreitador, funcionando como uma espécie de aviso à navegação, prevenindo o leitor de que o que vai ler não são "fábulas sonhadas". Antes fossem: "Não são isto, que fallo conjecturas,/ Oxalá forão fabulas sonhadas/ Da solta liberdade/ Mas ainda mal em fim, porque he verdade!" (Espreitador, I, 23; Aquino e Sousa 1880, 47).

10 A mesma ideia aparece reforçada no Barco da Carreira dos Tolos (1803), voltando José Daniel a pôr em confronto a mentira e a verdade, mas abrindo espaço aqui para uma verdade que, sem deixar de o ser, é apresentada de forma mais atraente - mais sexy, 
como diriam os especialistas em comunicação do século XXI: "Esta obra, que de ordinário he de Petas no nome, mas verdades infalliveis em substancia, adubadas com o sal da jocosidade, e até me parece, que dignas da applicação do Leitor mais sério", não faltando sequer uma referência a Horácio, "que foi hum galante sujeito" (Barco da Carreira dos Tolos, VII, 3). Já dois anos antes, no Comboy de Mentiras, o poeta romano era citado em lugar de destaque, a rematar o Prólogo:

Quando nesta composição houverem algumas graças insonsas, não obrigo os meus Leitores a que se rião dellas no mesmo dia, em que sahirem, bastará que se rião dahi a oito dias, porque eu não tenho maior pressa das gargalhadas, e se de todo lhe não acharem graça, rião-se de mim para terem sempre de que se rir, porém não percão de vista humas palavrinhas, que disse Horacio, quando andou pelo Mundo...: Quid rides? Mutato nomine, de te Fabula narratur. (Comboy de Mentiras, Prólogo ao Leitor, 4$)^{6}$

11 Sempre presente está o riso, aliado da verdade na correcção dos vícios:

[...] comprem, e lêão, acharão a repreensão dos vícios, sem determinação de pessoa, e o divertimento decente, que os provoque a riso, affecto da nossa alma tão preciso, que tem restituido a vida a milhões de pessoas: estas verdades mascaradas em todos os tempos corrigírão os vícios, (Barco da Carreira dos Tolos, VII, 4) ${ }^{7}$

Nestas vistas diversas apresento/ A justa correcção, que atalha o vicio:/ A crítica moral, que represento,/ Póde a muitos salvar do precipicio./ Misturo na lição divertimento,/ Faço aos génios estúrdios beneficio,/ Utilizo, aconselho, em tudo toco,/ Desnudando a Verdade, a rir provoco. (Câmara Óptica, I, 1)

\section{Verdade e mentira na guerra dos sexos}

12 Para estimular o interesse dos leitores - e leitoras -, José Daniel inventa polémicas. Recorrente nos sucessivos periódicos que editou foi a "guerra dos sexos". Um marido queixa-se exaustivamente dos defeitos da mulher até concluir: "Estas puras verdades, de que sem pejo o sexo femenino se ri, tendo-as por petas, são o nosso flagello, e de immensos indivíduos, que se calão, por não agravarem mais as suas feridas" (Almocreve, LXXXIV, 5).

13 No folheto seguinte publica a "Resposta que dá uma Senhora", rebatendo, ponto por ponto, o rol de queixas apresentado pelo homem, com um argumentário tão estereotipado como o primeiro. A réplica devolve as acusações e apresenta os homens como responsáveis dos "defeitos" das mulheres. ${ }^{8}$

[...] quasi todos os homens atirão ao nosso sexo, increpando-nos de defeitos, de que muitas vezes os homens são motivo, passo em nome de todas a advogar nesta causa [...]. Provará o nosso sexo, em defeza propria, com a verdade sabida, que o homem he huma Camera optica, onde com agradáveis côres se mostrão os vicios, e as virtudes, em continuada confusão. (Almocreve, LXXXV, 1-4)

\section{Fingimento}

Numa sociedade tradicional como era Portugal na viragem do século XVIII para o XIX, o lugar do indivíduo era, salvo raras excepções, imposto pelo nascimento. Querer subir na vida era dar o flanco para se ser exposto ao ridículo (Billig 2005, 200-202): os defensores da hierarquia estabelecida viam nisso, quase sempre, uma certa dose de fingimento, de querer parecer o que não se era (Minois 2000, 397 e 402-404).

Os periódicos de José Daniel Rodrigues da Costa fazem humor à custa de quem manifesta a ambição de mudar de estatuto social (Lisboa 2015, 355-357). Um exemplo 
deste tipo de troça que toma por alvo a burguesia ascendente é o poema sobre a multiplicação (e consequente desvalorização) do título dom antes do nome - a "praga de dons":

O moço do Poeta hindo huma noite destas assistir a hum casamento [...] vendo que em toda aquella companhia fervião os Dons, [...] desembrulhou-se este maroto daquela praga de Dons com o seguinte Soneto. Senhora Dona Moda chegue cá,/ Com Dona Contradança venha aqui;/ Porque a Dona Farofia agora ouvi/ Dizer, que já sem Dom Damas não ha:// A criada que esfrega, ou traz o chá,/ Com Dom em certa casa ha pouco vi;/ E se isto vai avante per ahi,/ O toque de Dom, Dom, em fogo dá.// Ha muitas que não tem dez réis de pão./ Querendo lhe dem Dom sem tom nem som,/ E só do ar do Dom vivendo vão:// Nada, meninas, isto não vai bom!/ Porque se acaso as modas nisto dão,/ Não vereis cão nem gato sem ter Dom. (Almocreve, LXXIV, 6-7)

Noutro texto do mesmo periódico, a sátira ao desejo de mobilidade social procura embaraçar os implicados, obtendo, assim, um efeito disciplinador: ${ }^{9}$

Hum Vossa Senhoria (de humas, que ha sem pés, nem cabeça) que vivia já enfastiado de Senhoria, e tinha grandissimos desejos de arrogar a si hum Vossa Excellencia, [...] chamou o seu Criado grave [...] de hoje em diante me dês o tratamento de Excellencia, este mesmo aviso farás aos moços da seje, e o communicarás ás pessoas que me procurarem [...]. Sahio logo o criadinho, [...] porém dando-lhe muito em que entender a quem ficaria a Senhoria, que seu Amo deixava; e porque não levava a bem que huma Senhoria deixada em tão bom uso se perdesse, tomou o partido de se cobrir com ella; foi descendo para a loja, e disse aos moços: olhem vossês que de hoje em diante devem tratar nosso Amo por Excellencia, e a mim por Senhoria [Ao jantar gerouse a confusão: entrou um boleeiro e, conforme fora industriado, tratou o criado por Vossa Senhoria, para espanto do patrão e dos seus convidados. O dono da casa exigiu uma explicação] epor onde te vem esse tratamento novo? disse o Amo: tornou-lhe o Criado: como sempre vi que os Criados tem todoodireito a tudo que seus Amos deixão, e V. Excellencia deixou a Senhoria de que usava, achei que não escandalisava a V. Excellencia em querer esta Senhoria para mim; porém se V. Excellencia inda tem tenção de se aproveitar da tal Senhoria, e leva isto amal, eu não devo usar de huma cousa contra vontade de seu dono: perdoe V. Excellencia, e eu largo a Senhoria outra vez, com a mesma brevidade com que $V$. Excellencia a deixou. Rírão-se todos muito, porém o Amo ficou com a Excellencia, e Senhoria atravessada na garganta de tal sorte, que não pôde mais naquella hora engolir bocado: Consta porém que como a Excellencia, e a Senhoria forão enxertadas, e o anno para enxertos, pelos frios que houverão tem corrido contrario, nem huma nem outra pegou. (Almocreve, CXII, 1-2)

O conformismo social é pregado com insistência. ${ }^{10}$ Nas "Máximas do Velho de Romulares", uma secção do Almocreve, sentencia: "Criado que se faz amo;/ Cabo que se faz Alferes;/ Mulher que em si põe o ramo;/ Tendeirinho com seus teres:/ Arrotão tantos poderes,/ Vomitão tanta pancada,/ Que do vomito no impulso/ Té vem postas de pescada" (Almocreve, CXXVII, 5). Os folhetos de O Espreitador contribuem com outros exemplos: "hoje que os criados, querem ser amos; os officiaes, mestres; os caixeiros, patrões; os escreventes, Letrados; os Alcaides, Ministros; e os filhos, donos da casa" (Espreitador, 2, 18). Outra mentira é aquela em que se baseia a vida dos ociosos, suscitando um dos textos mais violentos do autor. Aqueles "mandriões" e "sanguessugas" que passam o tempo nas "duas mil casas de café" de Lisboa"1 contrastam com os "ânimos honrados que se empregam em adquirir o que têm com o suor do seu rosto", de quem são o "flagelo eterno". A crítica da ociosidade, a par da do luxo, denota, apesar das já referidas declarações de adesão à ordem dominante, algum distanciamento relativamente ao modelo social baseado numa hierarquia com base no 
privilégio de nascimento, que só muito lentamente vai começando a admitir a mobilidade por mérito.

[...] por ter crescido o numero dos Mandriões, flagello eterno dos animos honrados, que tanto se empregão em adquirir o que tem, com o suor do seu rosto. Sabido he de todos que a ociosidade he a raiz lamentavel de todos os immensos individuos, que entregues a huma languidez se deixão cahir de preguiça nos braços da miseria, levados pelas mãos de seus enormes vicios! [...] Ha em Lisboa nada menos que duas mil casas de café; cada casa destas tem quatro effectivos da palestra de manhã, de tarde, e á noite recostados a huma meza, feitos esponjas dos abrasantes licores, que lhes servem de almoço, jantar, e ceia: Sendo pois as lojas duas mil, e estas a quatro palestrantes cada huma, temos infallivelmente oito mil homens ociosos, e humas esfaimadas sanguexugas, que de contínuo se lanção a chupar o sangue [dos] que trabalhão para o seu honesto, e decente passadio [...]. (Almocreve, CXXXIV, 1-3)

18 A esta mentira o autor opõe "O homem de bem, que se préza de Portuguez honrado [...]. Não anda mascarado com agrados, mentiras, e fingimentos" (Espreitador, 12, 13).

No entanto, esta adesão ao conformismo social pode, por sua vez, ser questionada: esconderá, num jogo de sombras entre petas e verdades encobertas, uma "recôndita revolta" (Palma-Ferreira 1974, 30). Essa "revolta" da linguagem discernível no periódico decorre da natureza ambígua do humor, que parece libertar, mas, ao mesmo tempo, controla, e por vezes de um modo cruel ou agressivo (Goatly 2012, 310).

\section{Verdades alternativas}

20 A citação de máximas, quase sempre em verso, é presença constante nos folhetos de José Daniel Rodrigues da Costa, marcando o "estatuto editorial" dos periódicos. Para marcar a continuidade entre o Almocreve de Petas e o Comboy de Mentiras, o editor cria uma relação de parentesco entre os respectivos autores: o Piloto da Barra, que dita sentenças no Comboy, é apresentado como neto do Velho de Remolares, iniciador da secção no Almocreve. Ao Piloto da Barra deve-se esta máxima orientadora da descoberta da verdade: "Destes pensamentos nús,/ Sem bellezas, sem enfeite/ Sempre o homem se aproveite,/ Que verdades descobrindo,/ Como me forão sahindo,/ Se escreverão" (Comboy, 3, 12).

21 É no Comboy de Mentiras que se encontra uma sequência de "bagatelas" que aproveitam a dimensão ambígua do humor para contar histórias brincando com verdades e mentiras. Num exercício de auto-irrisão, o autor começa logo por confessar ao que vai:

Por cartas vindas do Mundo novo (porque as trouxerão) se tem sabido muitas particularidades, que servem para encher papel, divertir os curiosos, e fazer-lhes exhibir o meio tostão, que custa este Folheto, que he o custo dos miólos de vacca presentemente [...], visto que a carestia anda entretida com tanta cousa, que mudou de preço. Nas mesmas cartas, que se recebêrão, vem relatada a seguinte particularidade. No lugar de Varejas faleceo huma menina de idade de dois annos, sete mezes, cinco dias, quatro horas, dez minutos, dois segundos, menos tres instantes e meio; foi irreparavel a perda do muito que pela duração da sua vida se podia esperar de vantagem, porque se esta menina, vivendo, se casasse aos quatorze annos, e fosse fecunda, daria á luz, no decurso de cinco annos, pelo menos, cinco filhos, e se continuasse a viver até á idade de cento e sessenta e três annos, como já se vio em hum homem da Noruega, conseguiria ter cento e quarenta e oito filhos [...]. Ora pelo mesmo Calculo he evidente, que se a tal menina falecida enviuvasse de cinco em cinco annos, contaria chegando aos cento e sessenta e tres annos, vinte e nove maridos [...] e se neste tempo lhe não tirassem, ou cahisse algum dente, os 
conservaria todos até morrer; de igual modo se não se lhe fizesse o cabello branco, iria com elle preto para a sepultura; em huma palavra se ella não morresse então, ainda hoje seria viva, porém como tudo vai das hipotheses, falhando estas, falhou tudo; este caso não deixa de dar alguma lição a todas aquellas pessoas, que passão por huma seara, e arrancão huma espiga verde, ou botão abaixo hum fructo verde de huma arvore, sem se lembrarem, que a perda daquelle grão, caroço, ou pevide priva a multiplicação, que podião produzir, bem como a morte cortou de hum golpe na vida desta menina a producção de tantas vidas. (Comboy, 7, 5-7)

\section{Postiços} Note-se, além de "encher papel, divertir os curiosos e fazê-los exibir o meio tostão", a presença da noção segundo a qual a alteração de qualquer pormenor no devir histórico tem consequências para o futuro, abrindo a possibilidade de conceber uma "história alternativa", central na literatura fantástica e na ficção científica.

A ambivalência das narrativas jocosas chega a ser assumida de forma explícita, como estas notícias dadas "com toda a certeza, se não for mentira", denotando um assinalável grau de cumplicidade com os leitores:

Por noticias de Constantinopla, se sabe com toda a certeza, se não for mentira, que os captivos daquele Reino se fintarão para fazerem hum rico presente ao Grão Senhor, a fim de lhes moderar o rigor do captiveiro, em que se achavão. Elles fizerão suas conferencias, nas quaes por superioridade de votos, resolverão offertar huma alampada para o Templo de Meca de extraordinaria grandeza, toda de prata guarnecida de pedras preciosas; porém de tal circunferencia, que posta no Templo, os Menistros delle para a accenderem, ou atiçarem, lhes he preciso despirem-se, e deitarem-se a nado no azeite para chegarem á luz. (Comboy, 22, 11) servem os postiços - "arte de compor", que ajuda a "disfarçar os defeitos do tempo e da natureza" cuja utilização, literal e metafórica, surge em dois periódicos. A história da noiva que depois do casamento se "desmancha", tirando dentes postiços, perna de pau e outras próteses é contada no Almocreve de Petas e na Câmara Óptica.

A mulher mais velha, viúva e "com fama de rica", que volta a casar-se com um homem mais novo é ridicularizada no Almocreve, que a aponta à discriminação de género, etária e social:

Havia neste bairro huma Senhora viuva de cincoenta e quatro annos de idade, a quem a arte de compôr ajudava a desfarçar os defeitos do tempo, e da natureza, era voz constante entre todos a fama de rica, segundo se colligia do seu tratamento, por cuja razão era igualmente requestada de immensos pertendentes para segundas Nupcias [...] chegado finalmente o ditoso dia, concluio-se este acto com a reunião de vontades dos dois Contrahentes, houve naquelle lance muita festa para a festa, as Aias, e os criados, todos de galla nova, o Noivo, e a Noiva de pannos largos, porque assim o pedia a função: terminada esta com a alta noite achava se o Noivo muito aflicto por ter reparado, que a Noiva todo o dia não tinha tirado a mão esquerda da cintura, e que de hum olho era a vista mais espantada que do outro, porém disfarçou o caso até chegar o tempo de tomar conta da casa, inda que já tinha recebido da mão da Noiva huma bolça com cem moedas de ouro por prenda [...] e como chegasse a hora de se recolherem [...] chamou a sua Aia para a despir [...] foi a Aia destoucando-a, e desenrolou-lhe hum horroso crescente de cabello achorinado, que a deixou calva de todo, e o Noivo vendo aquella desarmação ficou traspassado, depois, tirou-lhe a Aia hum olho de vidro [...]; passou depois a tirar- 
lhe o queixo debaixo, que deixou o Noivo de queixo cahido; e antes de lhe tirar o vestido principiou a Aia a alargar-lhe os laços de huma ligadura da banda do hombro direito que he donde prendia hum braço de páo, esquerdo, que suppria o que não tinha: o Noivo que se não podia já suster, acudio a isto dizendo: minha Senhora, ousa-me antes que se desfaça de todo; se se desarma por meu respeito, escusa ter esse incommodo, porque pela manhã ha de custar a soldar tanto bocado junto: eu a despenso de tudo, e por tudo, e concedame licença: pegou immediatamente no chapéo, e desceo pela escada abaixo: já dizem que se passou ao Alem- Téjo a contratar em presuntos com as cem moedas que recebêra, deixando a noiva ás boas noites. (Almocreve, CIII, 1-2)

Note-se a diferença em relação a outra história em quase tudo semelhante, relatada na Câmara Óptica. Neste periódico, o noivo responde à letra: "pois por estas que lhe não fico devendo nada!" (Câmara Óptica, IX, 4) - e começa a tirar um chinó, um olho de vidro, um braço de prata, etc. No dia seguinte, o casal tem dificuldade em identificar os respectivos dentes postiços: "verificando-se nisto que entre os casados, o que he de hum, he de outro" (Câmara Óptica, IX, 2-5).

\section{Bocage: soneto a uma comédia de enganos}

Sinal da popularidade das petas do Almocreve é o soneto "Ao machucho poetarrão", que lhe foi dedicado por Bocage. O poeta, que tinha por José Daniel Rodrigues da Costa e pelos seus folhetos um ódio de estimação, parodia um episódio narrado na Parte II do periódico, chamando-lhe "a obra melhor que tens composto" (Bocage 2004, 268-269).

Moiraria 24 de Fevereiro. Hontem á noite hia aqui succedendo huma desgraça formidável; juntárão-se em huma casa varios ranchos de Senhoras, para fazerem as comadres, havião alguns Margalhudos apaixonados, destes que campão pelos cabedaes, e nao pela sciencia, cujas cabeças são mais tabuletas de modas, que estantes de livros, e tomarão á sua conta a despeza de toda a cêa; mandarão ao Pasteleiro fazer com arroz hum gordo peru [...] chegárão-se as horas da cêa, e mandarão hum galucho, criado de hum Morgado do rancho, buscar a merendolla, eis que dous maganões sem casca [...] atracão o Galego, para lhe tirar o alguidar que levava o arroz, e o peru; e não obstante os gritos do mesmo Galego, elles mais espertos tiverão léo de lhe tirar o peru, e metter em seu lugar enterrado pelo arroz dentro hum gato morto, que acharão na rua: o Galego não via esta substituição, e mui lampeiro foi para casa poz-se a meza, veio sellada, azeitonas, vinhos, \&c., e o esperado peru, para que todos tinhão a guella aparelhada; foi o Morgado, amo do Galego, o eleito trinchante que entrou a talhar as pernas do gato, que estava encoberto no arroz, e as Senhoras, que comião, pasmavao, dizendo, que inda não tinhão visto perus calçudos, foi o trinchante abrindo a praça no referido alguidar, e ao mesmo tempo, descubrindo o corpo do pasmoso gato, que por estar ainda fresco, não deixava de fazer apetite; porém Senhoras, que quasi todas são de má boca, humas cuspião fora, outras tapavão o nariz com os lenços, a isto se ouvirão os apaixonados, café para a Senhora D. Fulana, licor á Senhora D. Sicrana, fumaças a humas, ventosas a outras, foi tal o labyrintho, que a bulha dos vómitos, e a bulha que fízerão os que acudírão, transtornou a casa da Assembléa em enfermaria de doidos porque de ordinário nas afílicções faz mais bulha quem acode, que quem padece; os visinhos de baixo, não sabendo do estratagema, já se achavão roucos de gritar pelos chuços, porém os filhos da chuxa não quizerão sahir, por se não constiparem; e como em casa onde não ha pão, todos ralhão, ninguem tem razão, brigárão as comadres, descobrírão-se as verdades, e aqui temos nova bulha; porque hum dos meus Senhores da função, por tolo, cahio em descobrir ser elle hum dos que vendêrão gato por lebre, de que se seguio miarem-lhe todos, e ficar muito bem 
arranhado de pescoções; e he para acreditar, que não tornará a ser inventor de peças, porque gato escaldado, \&c. (Almocreve, II, 3-4)

\section{Contra o anonimato e as "equivocações"}

29 Autor confesso das mais variadas petas, José Daniel Rodrigues da Costa aproveita o regresso ao convívio com os leitores em 1807, após um interregno de dois anos interrupção devidamente sublinhada, uma vez que, desde 1797, publicara sempre, de forma continuada, folhetos periódicos -, para, no Prólogo à Câmara Óptica, valorizar o seu trabalho e denunciar os imitadores:

[...] por mais que eu pedisse a minha dimissão na assembléa das Petas, para deixar de ser Author dellas, não me tem sido possível conseguilla, antes mil vezes me tenho visto perseguido pela curiosidade de innumeraveis pessoas, que levando muito a mal o meu silencio, tinhão reprehensivel ociosidade o estar eu callado no decurso de dous annos. Ha nisto de composições de Petas huma certa confusão, que me obriga a desenvolver os enganos, e equivocações, que girão nesta materia, só para que nem eu me figure usurpador do merecimento alheio, nem os outros campem á sombra da boa fé, que o respeitavel Público me tem concedido. He verdade que desde que me callei com o Hospital do Mundo, que conclui, tem sahido outras obras periódicas, que querem representar o meu estilo; e ainda que me não pertence analysar a sua bondade, ou apontar os seus defeitos, por não ir á aposta com os mais authores, como costumão fazer os rapazes da escola, com tudo não devo soffrer, que se me imputem obras, que não faço e para de huma vez dissipar esta preoccupaçao, fique o benigno Público desde já na certeza de que obra, que não leve o meu nome, não he minha. Nunca me ageitei a entrar no rol dos Anonymos, porque se a obra sahio feliz, não he desar ter o nome do Author, e se sahio informe, tenho valor, e animo para soffer a sangue frio a crítica merecida. (Câmara Óptica, Prólogo, iii-iv)

\section{“Epidemias"}

30 A profusão de "petas" e de periódicos apostados na emulação do pioneiro dão azo a peças, preferencialmente sob a forma de cartas e respostas a correspondentes, em que o autor é pródigo no auto-elogio e na autopromoção:

Carta que o Crítico de Evora mandou ao Author desta Obra. Ora para que Deos me tinha guardado! Para ler a Camara-optica de V. m.! Que seja possivel que havendo nas Estações algumas secas extensissimas, que tirão ás bocas do mundo o azeite, o pão, e o vinho, não venha huma por sua casa que lhe faça fome de petas! he pasmar! V. m. será alguma esponja, que chupe a si quantas petas ha no universo? Ninguém vive como V. m.: estabeleceo em petas todos seus fundos, e deo-se por seguro. Senhor, eu sabia que havia epidemia de febres, de bexigas, e de sarna; mas de petas só V. m. foi capaz de descubrir ao povo de Portugal. (Câmara Óptica, VII, 14)

31 Perante a "epidemia de folhetos", não hesita em classificá-los de "plagiários":

Forte epidemia de Folhetos appareceo no mundo depois da minha Collecção das Petas! Ora estes Senhores Escriptores do parlamento baixo, como eu que lho digo, não se desenganarão do desprezo, que merecem todos aquelles, que se fazem plagiarios? Em certo modo os que me pertendem imitar dão forças ao meu desvanecimento, porque me trazem á memoria que Virgilio imitou a Homero, Camões a Virgilio, e Cicero a Demosthenes; e quem mostra desejos de imitarme, nisso mesmo me concede algum merecimento [...]. Eu já apresentei a estes Senhores hum Almocreve, que levava; hum Comboy, que transportava; hum Espreitador, que observava; hum Barco, que conduzia; e hum Hospital, que curava! Que me resta 
agora? com efeito lembrou-me fazellos pasmar diante de huma Camara-Optica, aonde o mundo fosse visto ás direitas nas vistas postas ás avessas, representando-se nellas as cousas mais notaveis do tempo presente; e eis-aqui, e que se chama pôr a Vossas mercês a ver o Mundo por hum oculo. (Câmara Óptica, Prólogo, vi)

Dois anos antes já propusera o tratamento para a doença:

Achei que o Desengano (que cura tudo) era o melhor Medico para esta Enfermaria; e que de Enfermeiro devia servir o Tempo [...] isto de murmuração pega-se como carrapato a pêlo de cabra [...] e quem não he ignorante, sabe encubrir os seus defeitos. (Hospital, Prólogo, 7-9)

Década e meia mais tarde, com uma revolução e um novo regime político de permeio, viria a regressar ao tema, num soneto intitulado "Á multidão dos Impressos", incluído no opúsculo Ideias Vagas sobre Vários Assuntos, publicado em 1822, comparando a "periódica assoada" da época com as petas do pioneiro Almocreve:

Tenho ambos os olhos aggravados/ De ler a periodica assoada,/ Tudo em letra miúda, e tão cançada,/ Que vem os caracteres apagados:// Os Livreiros nas lojas affogados/ Estão com a infinita papelada;/ Parece praga aqui por Deos mandada,/ Qual a dos gafanhotos esfaimados!// Astro, Compilador, e Borboleta,/ Campeão, Patriotas, Pregoeiro,/ Correspondente, Portuguez, Gazeta!// Tenho em parolas gasto o meu dinheiro:/ Nem o meu Almocreve tanta peta/ Trouxe a Lisboa sendo tão peteiro! (Ideas Vagas, 16)

\section{Conclusão}

A mentira, tal como a loucura, é parceira do riso na longa genealogia do humor desde os gregos até à actualidade, passando pelas cantigas de escárnio medievais, pelos humanistas do Renascimento, pelo periodismo dos séculos XVII a XIX (Minois 2000, passim).

É a ambiguidade do humor que o torna capaz de desvendar a verdade para lá da peta, do ópio, do fingimento, da falsidade, cada um destes sinónimos de mentira com a respectiva gradação. No prólogo do Hospital do Mundo, o autor previne: "Muitos me chamarão mordaz, mas a estes perguntarei, se fallar verdade, sem prejuízo de terceiro, he hum crime?" (Hospital, Prólogo, 6).

O próprio conceito de mentira suscita reflexão e é questionado na sua relação com a verdade: "Com toda a certeza, se não for mentira" (Comboy, 22, 11). Esta relação, tal como aparece veiculada nos periódicos e outras obras de José Daniel Rodrigues da Costa, é bem mais complexa do que uma simples dicotomia, desenvolvendo-se num processo dialéctico - "petas com que tempero tantas verdades" -, exemplificado com a complexa relação que mantém com as suas fontes de informação:

E se me perguntarem quem tem a culpa de eu ser tão vasto nas Petas, com que tempero tantas verdades, responderei que as Senhoras, porque ellas mesmas com a macula de chocalheiras, que lhes vem por natureza, me procurão para me contarem cousas deles, e dellas... mais a mim, mais a mim, a qual mais ha de fallar, nutrindose todas de verem em praça pública os defeitos das suas similhantes; e eu neste caso acceitando, e requerendo, porque de tudo me sirvo para dar voltas á vida, visto que os tempos requerem estes tráficos. (Câmara Óptica, Prólogo, vi-vii)

Como lidar com a dificuldade em destrinçar a mentira da verdade? José Daniel propõese fazê-lo com alguma elasticidade:

Talvez, Senhores, que Vv. mm. cuidem, que o que se mostra nesta Camara-Optica, não seja o que vai pelo mundo, ou que se persuadão que são effeitos dos vidros, que 
augmentão, diminuem, e descompõe os objectos; pois não he assim: tudo quanto aqui se observa, he o mesmo que realmente acontece na vasta scena do mesmo mundo, onde parece que os dois primeiros, e principaes objectos, de que se compõe a divertida scena são a ridicularia, e a impostura. (Câmara Óptica, IX, 2) mentira e a verdade. Uma reacção em que participam, em quantidades generosas, a ambiguidade (Serna 2015, 18), o segundo sentido (Freud 2005, 89-98 e 364) e a inversão irónica (Jankélévitch 1964, 54-80).

41 É o próprio José Daniel quem reconhece ter sofrido dissabores em consequência da polissemia dos seus textos. Em Dezembro de 1808, ao justificar perante os leitores a longa interrupção dos folhetos da Câmara Óptica, refere-se pela primeira vez à conjuntura política e revela ter sido denunciado pela publicação de dois apólogos, interpretados como críticos do ocupante francês. ${ }^{12}$

Estimaveis Curiosos, e honrados Assignantes: as circumstancias dos tempos, e a malevolencia invejosa fizerão com que se não seguisse esta obra por espaço de alguns mezes, pois a má intenção disposta a prejudicar-me, por muitas vezes apontou o Apólogo das Árvores, que vem no quarto Folheto, e o da Lagartixa, que sahio no Folheto setimo, como duas Obras determinadas contra os nossos cruéis Protectores. Em parte não se enganavão; e como estes Apólogos admittião diversos sentidos, os que intentavam perseguir-me, fulminavão com a sua Analyse o risco de alguns desgostos por fruto do meu curioso trabalho. Então me dictou a prudencia, que seria melhor prevenir, do que emendar, justo motivo para pôr a minha penna em descanço [...]. Mas a pezar de tantos choques, que tem combatido a minha máquina, a ausência dos lubishomens de camisola me pôz tão forte, que se Lagarde ainda hoje existisse no Rocio (salva tal lugar) desafiava-o para ir á aposta com ele a respeito de Petas, para ver qual de nós cançava, se eu com as Petas dos Folhetos, se elle com as Petas das Gazetas. (Câmara Óptica, VIII, 1-3)

O comentário à actualidade política é raro nos folhetos de José Daniel Rodrigues da Costa, mas, quando a revolução de 24 de Agosto de 1820 pôs a nu a conflitualidade social até aí recalcada (Alves 2013, 12), o autor não se fez rogado. Um dos textos mais representativos deste período é um soneto incluído na recolha Ideias Vagas sobre Vários 
Assuntos intitulado "No presente estado das cousas", onde o autor esboça em duas penadas a situação de Portugal no concerto das potências europeias:

Contrato de mentiras, sem ter taxa,/ Em que algumas nos vem, que fazem brexa,/ Huns aos outros, na imprensa pondo péxa,/ Questões, em que a razão sempre se empaxa:// A Hespanha ora a dar alta, ora a dar baxa,/ Servis aos Liberaes chegando a mexa,/ Huma Santa Alliança, que se vexa,/ Vendo a Constituição, como se encaxa:// Inglez, que com cerveja tudo esguixa,/ E lucros para si somente puxa,/ De oculo a ver o Reino, que se espixa;// Assim por mar, e terra se extrabuxa;/ Morde aos Reinantes do ciúme a bixa,/ $\mathrm{E}$ os pobres he que vão soffrendo a buxa. (Ideias vagas, 22)

Eis como José Daniel combina, com particular felicidade - e pontaria -, a mentira, a verdade e o humor.

\section{BIBLIOGRAFIA}

Obras de José Daniel Rodrigues da Costa referidas no texto

1786. Opios que Dão os Homens e as Senhoras na Cidade de Lisboa Huns aos Outros: Tirados da Esperiencia do Author. Lisboa: Na Officina de Simão Thaddeo Ferreira.

1788a. Misturadas de Lisboa Temperadas à Moda, Pratinho em que Todos tem o seu Quinhão, ou a Segunda Parte dos Ópios. Lisboa: Na Officina de Simão Thaddeo Ferreira.

1788b. Petas da Vida ou a Terceira Parte dos Opios. Lisboa: Na Officina de Simão Thaddeo Ferreira.

1788c. Modas do Tempo, Descubertas na Quarta Parte dos Opios. Lisboa: Na Officina de Simão Thaddeo Ferreira.

1789a. Quinta Parte dos Opios em que Tem Cahido Muita Gente Boa. Lisboa: Na Officina de Simão Thaddeo Ferreira.

1789b. Resposta ao Contra-Opio, ou Defeza das Mulheres. Parte Sexta dos Opios. Lisboa: Na Officina de Simão Thaddeo Ferreira.

1795. Rimas Offerecidas ao Illustrissimo Senhor Theotonio Gomes de Carvalho por José Daniel Rodrigues da Costa, Entre os Pastores do Tejo, Josino, Leiriense. Lisboa: Na Officina de Simão Thaddeo Ferreira.

1819 [1. ed edição 1797-1800]. Almocreve de Petas, ou Moral Disfarçada, Para Correcção das Miudezas da Vida. Segunda Edição. Lisboa: Na Officina de J. F. M. de Campos.

1801. Comboy de Mentiras, Vindo do Reino Petista com a Fragata Verdade Encoberta por Capitania. Lisboa: Na Officina de Simão Thaddeo Ferreira.

1819 [1. a edição 1802]. O Espreitador do Mundo Novo. Obra Critica, Moral, e Divertida. Segunda edição. Lisboa: Na Officina de J.F.M. de Campos.

1850 [1. edição 1803]. Barco da Carreira dos Tolos. Obra Critica, Moral, e Divertida. Nova Edição. Lisboa: Typographia de Elias José da Costa Sanches.

1805. Hospital do Mundo. Obra critica, moral, e divertida, em que he Medico o Desengano, e Enfermeiro o Tempo. Lisboa: Na Officina de Simão Thaddeo Ferreira. 
1824 [1. edição 1807-1811]. Camara Optica. Onde as vistas ás avessas mostrão o mundo ás direitas. [2. edição]. Lisboa: Na Officina de J. F. M. de Campos.

1822. Idéas Vagas sobre Varios Assumptos para Recreio de Todas as Pessoas de Ambos os Sexos. Lisboa: Na Offic. de Simão Thaddeo Ferreira.

Referências bibliográficas

AGOSTINHO, Santo. 2007. “On Lying (De Mendacio)”. In Nicene and Post-Nicene Fathers First Series. Vol. III. St. Augustine, edited by Philip Schaff, 457-477. New York: Cosimo Classics.

ALVES, José Augusto dos Santos. 2013. Glória, Memória e Mito: O periodismo vintista (1820-1823). Porto: Edições Media XXI.

ANSELMO, Artur. 1997. "Fronteiras da História do Livro". Cultura IX: 15-22.

AQUINO, Thomas J., e Manuel de Faria e Sousa. 1880. Vida de Camões. Porto: Imprensa Commercial. https://archive.org/stream/avidadecames00sousgoog/avidadecames00sousgoog_djvu.txt. Consultado em 15-03-2016.

ARAÚJO, Ana Cristina. 2009. "Vocabulário, imagens e modalidades irónicas de comunicação política em finais de Antigo Regime. O caso de José Daniel Rodrigues da Costa”. In Actas do IV Congresso Histórico de Guimarães - Do Absolutismo ao Liberalismo, 147-173. Guimarães: Câmara Municipal de Guimarães.

BERGSON, Henri. 1991. O Riso. Tradução de Miguel Serras Pereira. Lisboa: Relógio D'Água. BILLIG, Michael. 2005. Laughter and Ridicule: Towards a social critique of humour. London: SAGE Publications.

BOCAGE, M. M. Barbosa du. 2004. Obra Completa, edição de Daniel Pires. Vol. 1. Porto: Caixotim. BOURGUINAT, Elisabeth. 2000. "Rire et pouvoir : La leçon du persiflage libertin". Dix-huitième siècle : Le Rire 32: 279-290.

CONSTANT, Benjamin. 1796. des réactions politiques. Seconde Édition, augmentée de l'examen des effets de la terreur. Paris: s.n. https://gallica.bnf.fr/ark:/12148/bpt6k6267088v/. Consultado em 19-03-2016.

DELIGNE, Alain. 2011. "De que maneira o riso pode ser considerado subversivo?". In Imprensa, humor e caricatura: A questão dos estereótipos culturais, organização de Isabel Lustosa, 29-46. Belo Horizonte: Editora UFMG.

DERRIDA, Jacques. 2012. Histoire du mensonge. Prolegomènes. Paris: Editions Galilée.

DRUCKER, A., O. Fein, D. Bergerbest e R. Giora. 2014. “On sarcasm, social awareness, and gender". Humor 27 (4): 551-573.

ESCARPIT, Robert. 1960. L'Humour. Paris: Presses Universitaires de France.

FERREIRA, Maria Isabel Lopes. 2011. “José Daniel Rodrigues da Costa (1755/56-1832). Um autor ao serviço da 'educação dos povos”', Dissertação de Mestrado em Estudos Românicos, Departamento de Estudos Românicos da Faculdade de Letras da Universidade de Lisboa.

FRANÇA, José-Augusto. 2008. Lisboa: História Física e Moral. Lisboa: Livros Horizonte.

FREUD, Sigmund. 2005. Le Mot d'esprit et sa relation à l'inconscient. Paris: Gallimard.

GOATLY, Andrew. 2012. Meaning and Humour. Cambridge: Cambridge University Press.

JANKÉLÉVITCH, Vladimir. 1964. L'Ironie. Paris: Flammarion. 
KANT, Immanuel. 1997. "Sobre um Suposto Direito de Mentir por Amor à Humanidade”. Tradução de Artur Morão. http://www.lusosofia.net/textos/

kant_sobre_um_suposto_direito_de_mentir.pdf. Consultado em 18-03-2016.

LISBOA, João Luís. 2011. “O Anatômico entre os papéis jocosos setecentistas”. In Imprensa, Humor e Caricatura: A questão dos estereótipos culturais, organização de Isabel Lustosa, 391-405. Belo Horizonte: Editora UFMG.

LISBOA, João Luís. 2015. "Read, watch and laugh (with eighteenth-century humorous books)". In Views on Eighteenth Century Culture, Design, Books and Ideas, edited by Leonor Ferrão and Luís M. Bernardo, 346-357. Cambridge: Cambridge Scholars Publishing.

MARTINS, Maria Teresa Payan. 2005. A Censura Literária em Portugal nos Séculos XVII e XVIII. Lisboa: Fundação Calouste Gulbenkian e Fundação para a Ciência e a Tecnologia.

MINOIS, Georges. 2000. Histoire du rire et de la dérision. Paris: Fayard.

NIETZSCHE, Friedrich. 1997. “Acerca da Verdade e da Mentira no sentido extramoral (versão de 1873)”. In O Nascimento da Tragédia e Acerca da Verdade eda Mentira, 213-222. Lisboa: Relógio d'Água.

PALMA-FERREIRA, João. 1974. O Almocreve de Petas e outras prosas. Selecção, prefácio, leitura e notas. Lisboa: Estúdios Cor.

PEREIRA, José Esteves. 1992. Sobre a História das Ideias. Lisboa: Centro de História da Cultura/UNL.

PIRANDELLO, Luigi e Teresa Novel. 1966. “On Humor”. The Tulane Drama Review 10, No 3: 46-59.

QUINTERO, Ruben. 2007. “Understanding Satire”. In A Companion to Satire, edited by R. Quintero, 1-11. Oxford: Blackwell Publishing.

SALIBA, Elias Thomé. 2002. Raízes do Riso. A representação humorística na história brasileira: da Belle Époque aos primeiros tempos do rádio. São Paulo: Companhia das Letras.

SERNA, Pierre. 2015. "Ou morts d'en rire". In La Politique du Rire: Satires, caricatures et blasphèmes XVIe-XXIe siècles, direction de P. Serna, 11-47. Ceyzérieu: Champ Vallon.

\section{NOTAS}

1. José Daniel Rodrigues da Costa foi, provavelmente, o autor mais prolífico das letras portuguesas do seu tempo: poeta, dramaturgo, redactor, editor - além de funcionário do fisco (protegido do intendente da Polícia Pina Manique e do magistrado irmão deste), oficial da Legião do Paço da Rainha e ainda, sempre que a oportunidade se oferecia, vendedor dos seus folhetos (Ferreira 2011).

2. Sobre as Protestações e o seu papel nas obras do século XVIII, ver Anselmo 1997, 20.

3. ANTT. Desembargo do Paço, Corte, Estremadura e Ilhas, Maço 682, caixa 603, apud Martins 2005, 82, nota 1. A cópia do documento foi gentilmente cedida pela Prof.․ Doutora Maria Teresa Payan Martins.

4. Concepção próxima da "turina" do Anatómico Jocoso (Lisboa 2011, 391-405).

5. A série de poemas com a designação genérica de ópios foi um dos primeiros êxitos editoriais de José Daniel, publicada em seis partes, entre 1786 e 1789 (Costa 1786, 1788a, 1788b, 1788c, 1789a, 1789b).

6. "Quem ri? Muda-lhe o nome e a história fala de ti" ou "Mudado o nome, é de ti que a história fala”, Horácio. Sátiras. Livro 1, Sátira 1. A mesma citação é colocada por Marx no prefácio à 1. edição de 0 Capital, para justificar a escolha da Inglaterra como "ilustração principal" da sua investigação sobre o modo de produção capitalista. 
7. Ao assumir esta posição, José Daniel Rodrigues da Costa integra-se numa longa tradição (Minois 2000, 49-53 e 347-349; Quintero 2007, 1-11).

8. Para uma reavaliação do sarcasmo no humor baseado na percepção do papel social do género, ver Drucker et al. 2014, 551-573.

9. Billig sublinha a dimensão socializadora e disciplinadora do ridículo e a relação ambivalente entre o embaraço e o humor na sua função social: "It can function to protect the social order, keeping social actors in line, but simultaneously it can express pleasure at subverting that same order [...]. One might suppose that ridicule is universally useful both as a means of socialization and as a means of preserving everyday social order through the disciplines of embarrassment" (Billig 2005, 235).

10. Sobre o "potencial coercivo" do riso e o "riso conservador", ver Minois 2000, 197-198.

11. Número exagerado mas que, no contexto das "petas", visa transmitir a ideia do grande número de cafés e da sua propagação acelerada em diferentes locais da cidade. José-Augusto França sublinha o papel destes "cafés, tendinhas e botequins" para a "pequena boémia poética e intelectual" (França 2008, 479).

12. Sobre o contributo de José Daniel para a propaganda antinapoleónica, ver Araújo 2009, 171-173.

\section{RESUMOS}

A ambiguidade do humor torna-o capaz de desvendar a verdade para lá da peta, do ópio, do fingimento, da falsidade - cada um destes sinónimos de mentira está presente, com subtis gradações, nos periódicos de José Daniel Rodrigues da Costa. O próprio conceito de mentira suscita reflexão e é questionado na sua relação com a verdade: "Com toda a certeza, se não for mentira." o exagero das petas com que "tempera" as verdades chama a atenção dos leitores para a "verdade encoberta" sob as convenções das práticas sociais, numa dialéctica do ser com o dever ser, do moral com o amoral, na fronteira entre o lícito e o ilícito nas últimas décadas do Estado absolutista e no dealbar do liberalismo. 0 estudo do humor, dos seus limites e do seu lugar nos periódicos na viragem do século XVIII para o XIX é uma das muitas formas da história das ideias.

The ambiguity of humour enables it to disclose the truth behind the fib, the pretence, the deceit. Each one of these synonyms of lies is at work, with its own subtle gradation, in the periodicals edited by José Daniel Rodrigues da Costa. The very notion of lie arouses careful consideration and is called into question in its relationship with truth: "With all certainty, if it is not a lie." The exaggeration of the fibs with which Da Costa "spices" the truths draws attention to the "hidden truth", concealed under the cover of social convention, in a dialectic of what is and ought to be, the moral and the amoral, in the border between licit and illicit in the final years of absolutism and the threshold of liberalism. The history of humour, its boundaries and its place in the periodicals of the late 18th and early 19th centuries is one of the many shapes of the history of ideas. 
ÍNDICE

Keywords: humour studies, periodical press, history of the book and writing, history of ideas Palavras-chave: humor, imprensa periódica, história do livro e da leitura, história das ideias

\author{
AUTOR \\ JOÃO PEDRO ROSA FERREIRA \\ CHAM, FCSH, Universidade NOVA de Lisboa, Portugal; Bolseiro de Doutoramento da FCT (SFRH/ \\ BD/117704/2016).jprosaferreira@gmail.com \\ Mestre em História Cultural e Política e doutorando em História e Teoria das Ideias, tendo em \\ preparação a tese "Castigar a rir. O humor na imprensa periódica portuguesa (1797-1834)". \\ Bolseiro de Doutoramento da FCT (SFRH/BD/117704/2016), é investigador do grupo "Leitura e \\ formas da escrita" do CHAM. Publicou O Jornalismo na Emigração, além de vários capítulos de \\ livros, artigos científicos e livros de divulgação. É membro da Sociedade Internacional para o \\ Estudo do Humor Luso-Hispânico. \\ MA in Cultural and Political History and PhD candidate in History and Theory of Ideas, with a \\ grant from Fundação para a Ciência e a Tecnologia (SFRH/ BD/117704/2016). His thesis deals with \\ humour in Portuguese periodicals from 1797 to 1834 . A research fellow in the group "Reading \\ and the forms of writing" at CHAM, he has published O Jornalismo na Emigração, as well as several \\ articles and chapters of books. He is a member of the International Society for Luso-Hispanic \\ Humor Studies.
}

